\title{
Community-Engaged Neighborhood Revitalization and Empowerment: Busy Streets Theory in Action
}

\author{
Laney A. Rupp, ${ }^{1}$ iD Marc A. Zimmerman, ${ }^{1}$ Kathleen W. Sly, ${ }^{1}$ Thomas M. Reischl, ${ }^{1}$ (D) Elyse J. Thulin, ${ }^{1}$ (D) \\ Thomas A. Wyatt, ${ }^{2}$ and John (Jack) P. Stock ${ }^{2}$
}

\author{
Highlights \\ - Busy streets theory supported in qualitative study of neighborhoods in a rust belt city. \\ - Community engaged neighborhood improvement enhances psychological empowerment. \\ - Resident control of neighborhood revitalization results in most empowered outcomes of busy streets.
}

(C) 2019 Society for Community Research and Action

\begin{abstract}
Busy streets theory predicts that engaging residents in physical revitalization of neighborhoods will facilitate community empowerment through the development of sense of community, social cohesion, collective efficacy, social capital, and behavioral action. Establishing safe environments fosters positive street activity, which reinforces neighborhood social relationships. A community-engaged approach to crime prevention through environmental design (CE-CPTED) is one promising approach to creating busy streets because it engages residents in collaborative interactions to promote safer environments. Yet, few researchers have studied how CE-CPTED may be associated with busy streets. We interviewed 18 residents and stakeholders implementing CE-CPTED in Flint, Michigan. We studied three neighborhoods with different levels of resident control over CE-CPTED. Participants described how CE-CPTED implementation affected their neighborhood. Participants from all three neighborhoods reported that CE-CPTED was associated with positive street activity, sense of community, and collective efficacy. Participants from neighborhoods with higher resident control of CE-CPTED reported more social capital and behavioral action than those from neighborhoods with less resident control. Our findings support busy streets theory: Community engagement in neighborhood improvement enhanced community empowerment. CE-CPTED that combines
\end{abstract}

$\triangle$ Laney A. Rupp

laneyr@umich.edu

1 University of Michigan, Ann Arbor, MI, USA

2 Kettering University, Flint, MI, USA physical revitalization with resident engagement and control creates a potent synergy for promoting safe and healthy neighborhoods.

Keywords Busy streets - Community empowerment . Neighborhood safety. Crime prevention through environmental design

\section{Introduction}

Busy streets theory (BST) is a reframing of deficit-oriented theories of neighborhood safety (Aiyer, Zimmerman, Morrel-Samuels, \& Reischl, 2015). BST specifies how neighborhood residents and community organizations can be agents of positive neighborhood transformation that support neighborhoods to re-establish as safe and empowered environments. BST offers an opposing perspective to broken windows theory (Kelling \& Coles, 1997; Kubrin \& Weitzer, 2003; Wilson \& Kelling, 1982) and other social disorganization theories that emphasize the role of physical disorder, residential instability, poverty, and diminished social control in neighborhood decline (Garvin, Branas, Keddem, Sellman, \& Cannuscio, 2013; Sampson, Raudenbush, \& Earls, 1997; Wilson \& Kelling, 1982). While these theories provide a broad understanding of how neighborhoods deteriorate, they do not help to explain how neighborhoods re-establish themselves to be safe and positive contexts for human interaction. In contrast, busy streets theory provides a model for creating safe and empowered neighborhoods.

Busy streets theory focuses on the process of creating safe and empowering contexts that are characterized by 
observable activity and social features of neighborhoods. Observable activity of busy streets includes the use of streets for walking and biking, and visible pro-social interaction that signals an environment where residents demonstrate social control, social capital, and investment in their neighborhood (Aiyer et al., 2015).

Social features of busy streets include the positive neighborhood perceptions, social and organizational linkages, and behaviors that residents need to promote neighborhood connectedness and improve neighborhood conditions. Social features of busy streets parallel psychological empowerment (Perkins \& Zimmerman, 1995) and organizational empowerment (Peterson \& Zimmerman, 2004) constructs and are exemplified by the development of sense of community, social cohesion, collective efficacy, social capital, social control, and behavioral action (Aiyer et al., 2015).

Sense of community refers to residents' perceptions of their neighborhood, including their sense of belonging, pride, and morale (McMillan \& Chavis, 1986; Sarason, 1974). Social cohesion refers to the sense of connectedness among residents and their willingness to help each other (Durkheim, 1997). Collective efficacy represents residents' beliefs that they have the capacity to create safer and more connected neighborhoods (Sampson et al., 1997). Collectively, these empowered perceptions support residents to invest in their environment and build a critical psychological foundation for involvement in neighborhood improvement. Social capital refers to supportive linkages neighborhoods have with each other and organizations (e.g., local businesses) and institutions (e.g., police) that provide resources for community improvement (Coleman, 1988). Social control refers to standards of behavior that resist illicit and other nefarious activity and includes surveillance behaviors and property maintenance intended to communicate these standards (Sampson \& Laub, 1995). Finally, behavioral action refers to the actions residents take in partnership with other organizations and institutions to improve their neighborhood (Aiyer et al., 2015). The process of improving the physical environment in collaboration with neighbors and organizational partners can establish more positive settings and opportunities for social interaction and engagement in neighborhood life, thereby fostering protective social connections and resources (Aiyer et al., 2015).

Aiyer et al. (2015) suggest that BST articulates a process for developing empowered communities because it posits that engaging residents in physical revitalization of their neighborhood will accelerate the development of safe, organized, and active places. Engaged residents' perceptions of their neighborhood are expected to improve, new social resources are expected to develop, and positive behaviors that begin to transform their neighborhood are expected to grow. BST also suggests that residents' engagement in physical revitalization activities will create organized neighborhoods that signal ownership and invite positive social interaction, thereby reinforcing neighborhood connectedness, safety, and vitality. Thus, BST helps explain the upward spiral of positive physical and social neighborhood transformation (vs. the downward spiral often associated with broken windows theory). While BST provides a conceptual framework for how safe and empowered neighborhoods may develop, a crime prevention through environmental design (CPTED) approach (Jacobs, 1961; Newman, 1973, 1996) represents one possible strategy to promote busy streets.

\section{Crime Prevention Through Environmental Design}

Early conceptualizations of CPTED strategies focused on improving physical features of urban neighborhoods to demonstrate that an area is owned, maintained, visually monitored, and protected from unwanted entry (Jacobs, 1961; Newman, 1973, 1996). Examples of CPTED strategies include landscaping or mowing properties to signal ownership, clearing brush or installing security lighting to increase visibility, and boarding windows to prevent unauthorized access. These physical CPTED strategies create defensible space that reduces opportunities for crime and violence while promoting a sense of ownership and safety for residents (Cozens \& Love, 2015; Crowe, 2000; Newman, 1972). More recent conceptualizations of CPTED include social strategies that provide opportunities for community residents to plan and implement neighborhood improvements, take ownership of community spaces, and establish connections across neighborhoods and organizations to build resources for change (Cozens \& Love, 2015; Saville \& Cleveland, 2013).

Researchers have provided initial evidence that making physical CPTED improvements to neighborhoods may facilitate positive social features of busy streets, including an enhanced sense of community and social cohesion (Abdullah, Hedayati Marzbali, \& Maghsoodi Tilaki, 2013; Kuo, Sullivan, Coley, \& Brunson, 1998; Skjaeveland \& Garling, 1997). Kuo et al. (1998) found that planting trees predicted greater utilization of public gathering spaces and increased positive social interaction and social ties. Skjaeveland and Garling (1997) similarly found that residents who perceived more positive neighborhood spaces to interact reported more neighboring behaviors and attachment relative to residents who perceived less space to engage with neighbors. Abdullah et al. (2013) found that residents who adopted physical CPTED strategies to secure their homes perceived more social cohesion relative to residents who adopted fewer CPTED strategies. Yet, these projects focused exclusively on physical CPTED 
change and did not focus on community engagement in the revitalization process. In contrast, we assess whether interventions that combine physical revitalization, resident engagement, and organizational support can help the emergence of observable activity and social features associated with busy streets. Our study provides an opportunity to directly examine how the synergistic application of physical and social CPTED strategies, which we refer to as community-engaged CPTED (CE-CPTED), may build positive physical and social climates indicative of busy streets.

\section{Resident Control and CE-CPTED Effects}

Notably, CE-CPTED may involve different levels of resident control in the revitalization process. High levels of resident control are characterized by initiatives in which community residents and organizations plan change activities collaboratively, exercise shared decision-making power, and work together to implement changes. Lower levels of resident control in CPTED implementation are characterized by initiatives in which residents are not involved in planning the change activities and do not have decision-making power, but do participate in organizationled CPTED activities (Arnstein, 1969). The degree to which residents are involved in planning and implementing CE-CPTED may influence the extent to which busy streets are realized. Structural features of neighborhoods (e.g., home ownership, vacancy, population density, socioeconomic resources) may also influence the level of citizen investment and engagement in CPTED activities and therefore the creation of busy streets (Reynald, 2011).

The primary purpose of this study is to (a) examine how the implementation of CE-CPTED strategies may be associated with features of busy streets and (b) explore how variance in resident control over CE-CPTED intervention activities may affect the strength of the relationship between CE-CPTED and busy streets outcomes. We studied three neighborhoods with different levels of resident control in the CPTED process and varying structural features. We present findings from in-depth interviews with residents and organizational partners who were involved in implementing CE-CPTED to assess BST constructs across these neighborhoods. We expected that features of BST would be most evident in the neighborhood with the greatest resident control and less evident as resident control diminished. That is, respondents in neighborhoods with more resident control over CE-CPTED would report a stronger sense of community, social cohesion, collective efficacy, social capital, social control, and behavioral action that those with less control. Our collaborative work with neighborhood development organizations in Flint, MI, has provided an opportunity to observe and document a neighborhood revitalization using a CECPTED approach, and to examine concomitant features of BST that are expected to result from the process.

\section{Method}

\section{Study Context and Partners}

During the 1960s, Flint was a thriving automotive manufacturing center with over 80,000 jobs at local General Motors factories. Since the 1970s, however, Flint lost $90 \%$ of its auto industry jobs and the resulting 50\% decline in population created critical challenges in the physical and social environment (Frohlich, 2016). Flint's population fell from 196,940 (in 1960) to 96,488 (in 2016), and the city currently has the largest percentage of vacant homes in the nation at $12.5 \%$ of residential units (U.S Census Bureau, 1960, ). High vacancies and increased physical deterioration attract crime, contribute to breakdowns in social capital, and reduce neighborhood resources for deterring crime and violence (Garvin et al., 2013). Yet, results from a community survey highlight the resiliency of Flint communities, with up to $36 \%$ of Flint residents reporting involvement in neighborhood improvement activities (Genesee County Health Department, 2013).

The focus area for this study is a 3.2 square mile area adjacent to Flint's downtown business district, called the University Avenue Corridor (UAC). In 2008, several organizations in the UAC area conducted community improvement activities, but these efforts involved few residents, were more episodic than sustained, and more sitespecific than neighborhood-wide. One local community development corporation, for example, worked to promote a positive identity for the corridor by changing the name of the corridor's central road from 3rd avenue to University Avenue. The activity of this organization diminished over time, and community improvement efforts in the corridor lost momentum during the economic recession later that year.

As federal recovery dollars became available, however, a local Flint Weed and Seed chapter began to focus on crime prevention and economic development. They secured funding for a job training program that involved ex-offenders in cleanups and property maintenance in the University Avenue Corridor area and surrounding neighborhoods. The project ended in early 2012, but the program's focus on improving the physical environment of the corridor helped set up what was to become the University Avenue Corridor Coalition (UACC). Subsequently, the Weed and Seed chapter secured funding for a month-long training and technical assistance program 
organized by the National Crime Prevention Council (NCPC). The training focused on applying the CPTED methodology to reduce crime and revitalize corridor neighborhoods. Concurrently, Kettering University, a local engineering institution, appointed a new president who championed community vitality as a strategic priority. Kettering University joined with the Flint Weed and Seed program to host the NCPC-led CPTED planning workshops for the University Avenue Corridor.

Discussions at the CPTED workshops resulted in a consensus that attendees needed to take action to improve their environment because city services had been severely cut due to budgetary crisis. Attendees formed the University Avenue Corridor Coalition (UACC) to carry out collaborative strategies to improve the corridor. The UACC selected CE-CPTED as their primary strategy for community improvement because they recognized that improving the appearance and security of the corridor was a vital step to reduce crime and to encourage residents and businesses to return to the area. Coalition members signed a document of understanding to guide their work and have met monthly since the coalition's formation.

Founding partners of the UACC included Kettering University, Flint's largest public hospital, Hurley Hospital, and a local homeless shelter, Carriage Town Ministries. These organizations took a leadership role in the implementation of CE-CPTED activities across the corridor, and Kettering University served as the fiduciary agent for grants awarded to the coalition. UACC membership has since expanded to more than 100 community-based organizations, hospitals, universities, and law enforcement agencies. These partners have engaged local residents to identify, plan, and implement more than 200 unique CPTED activities since the coalition's inception.

The goal of UACC-led CE-CPTED activities was to reduce crime and improve neighborhood social life by establishing ownership, improving sight lines, and sending environmental messages that residents care about their neighborhood (Cozens \& Love, 2015). This more strategic CE-CPTED approach was also locally owned, supported by the coalition of organizations in the corridor (i.e., UACC), and included an intentional effort to engage residents in the CE-CPTED process.

Study Neighborhoods: CE-CPTED Intervention Activities and Resident Control

Our analysis focused on three neighborhoods in the University Avenue Corridor area: Carriage Town, Stevenson, and Mott Park. A map of the study neighborhoods is presented in Fig. 1.

These neighborhoods have all experienced high poverty and low housing values (Feyrer, Sacerdote, Stern, Saiz, \&
Strange, 2007; Schilling \& Logan, 2008; U.S. Census Bureau, 2015a, 2015b) (see Table 1).

Yet, the neighborhoods differed on key structural features, existing resources for community development, and level of control over CE-CPTED exercised by neighborhood residents. We describe below how the three neighborhoods compared in this study varied in their structural features, CE-CPTED strategies applied, and the level of resident control over CE-CPTED.

\section{Carriage Town Neighborhood}

Carriage Town is a city-designated historic district because it is one of Flint's oldest neighborhoods and includes General Motors first factory building. This 0.25 square mile (ESRI, 2019), mixed residential neighborhood had several small businesses, including a locally run grocery store, gas station, and sandwich shop. Housing consisted of primarily larger single-family homes, many of which had been divided into multifamily buildings (U.S. Census Bureau, 2015a, 2015b). While Carriage Town had the highest property values of the three study neighborhoods, the neighborhood had low residential stability, including high vacancies and few owner-occupied homes. Recent census data indicated that over two-thirds of neighborhood residents were renters and less than $10 \%$ were long-term residents who had moved into the neighborhood prior to 2000 (U.S. Census Bureau, 2015a, 2015b). A UACC needs assessment identified a cluster of vacant properties on the neighborhood's west side, including a liquor store and adjacent vacant lot as an epicenter of violent and property crime (Berge \& Reischl, 2015). An existing neighborhood association prioritized maintaining the historic district boundary and rehabilitating these properties (Fonger, 2014b).

CE-CPTED activities. CE-CPTED activities in Carriage Town began in the first year of the UACC's activity with a focus on addressing crime-generating sites. The UACC determined to focus on the Carriage Town neighborhood first due to immediate safety concerns surrounding a crime-attracting liquor store. The store was located on a major road that served as the key access point to the corridor and institutions including Kettering University, Hurley Hospital, and Flint's downtown. This prominent, high-traffic location made the criminal activity that occurred around it immediately visible, with adverse effects for public perception and positive use of the area. Once coalition leaders became aware of the crime patterns surrounding the liquor store and its negative effects on residents and employees, Carriage Town was selected as the immediate priority for CE-CPTED intervention.

The UACC leadership initiated major structural changes, including negotiating the purchase and closure of the liquor store. In its place, UACC partners built a fast- 


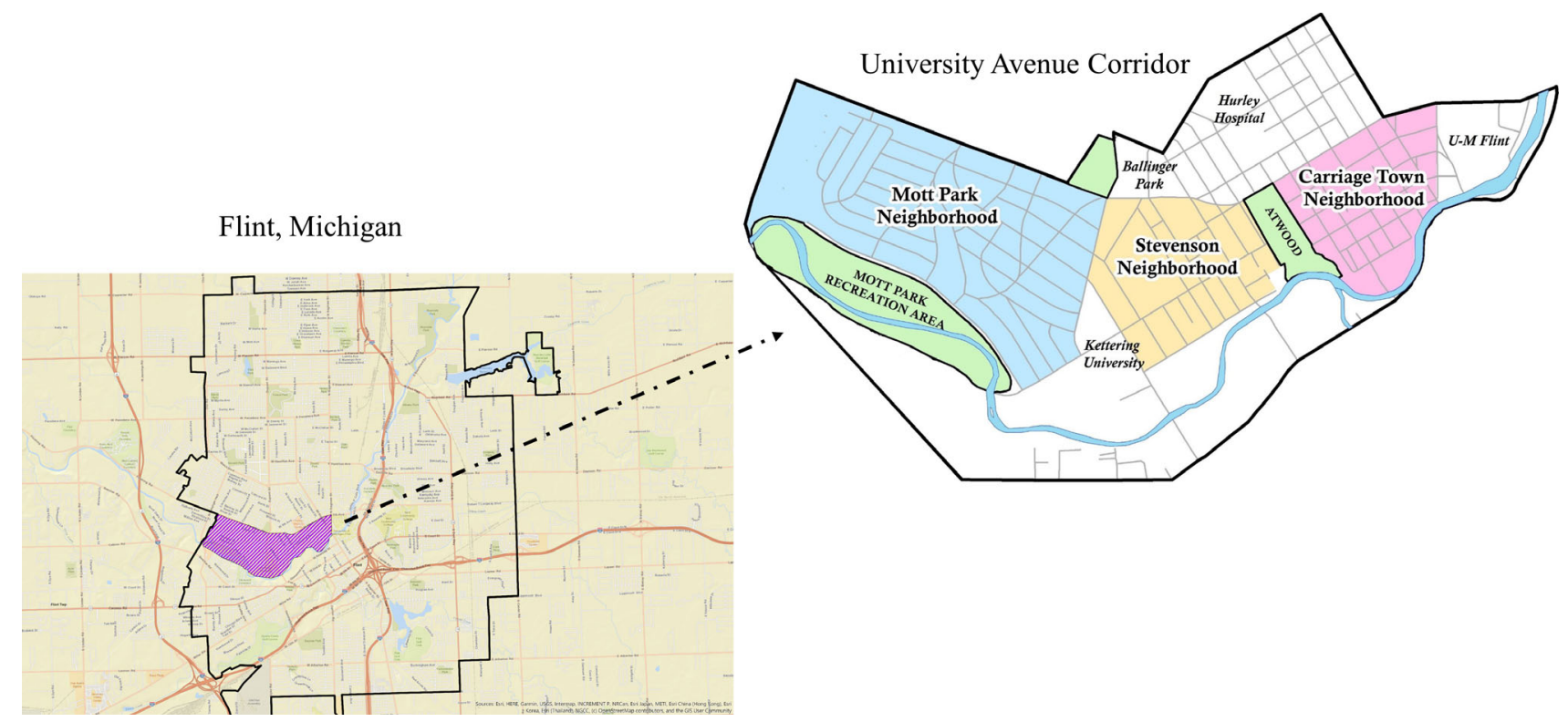

Fig. 1 Map of the University Avenue Corridor study neighborhoods in Flint, Michigan [Color figure can be viewed at wileyonlinelibrary.c om]

Table 1 Demographic characteristics of the three study neighborhoods

\begin{tabular}{lccc}
\hline & \multicolumn{3}{c}{ Neighborhood } \\
\cline { 2 - 4 } & $\begin{array}{c}\text { Carriage } \\
\text { Town }\end{array}$ & Stevenson & $\begin{array}{c}\text { Mott } \\
\text { Park }\end{array}$ \\
\hline Neighborhood demographics & a & & \\
Population count & 786 & 443 & 3251 \\
Percent families (presence of & 38.8 & 64.3 & 43.6 \\
child $>18$ years) below & & & \\
poverty (\%) & & & \\
Percent White (\%) & 48.9 & 39.7 & 50.3 \\
Percent Black or African & 41.1 & 56.8 & 44.7 \\
$\quad$ American (\%) & & & \\
Median household income & $\$ 19,252$ & $\$ 14,964$ & $\$ 30,099$ \\
Median value owner/occupied & $\$ 62,878$ & $\$ 28,332$ & $\$ 37,106$ \\
house & & & \\
Vacancy (\%) & 37.6 & 43.2 & 5.0 \\
Housing units & 400 & 316 & 1,277 \\
Owner-occupied units (\%) & 25.7 & 36.4 & 55.8 \\
Renter-occupied units (\%) & 74.3 & 63.6 & 44.2 \\
Tenure (year householder moved into unit) & & \\
2015 or later (\%) & 5.3 & 0 & 1.4 \\
2010-2014 (\%) & 51.7 & 65.0 & 43.1 \\
2000-2009 (\%) & 33.7 & 15.6 & 28.7 \\
Before 2000 (\%) & 9.3 & 19.3 & 25.8 \\
\hline
\end{tabular}

${ }^{a}$ The estimates were based on weighted estimates of overlapping block group statistics gathered from the American Community Survey dataset (U.S. Census Bureau, 2015a, 2015b).

food restaurant building, recruited a national sandwich shop franchise to the site, and converted a large, adjacent vacant lot into a neighborhood park. The UACC leadership also supported a proposal to revise the boundaries of the historic district by removing 10 blocks, because they perceived that this revision would make it easier and less expensive to make physical changes to the neighborhood, including demolishing or remediating crime-attracting structures (Fonger, 2014a). The UACC leadership subsequently collaborated with the local Land Bank Authority, an agency responsible for acquiring, managing, and revitalizing vacant and foreclosed properties, to purchase and demolish the problematic, abandoned structures (Kildee \& Hovey, 2019). The UACC also initiated more small-scale CE-CPTED activities including daily litter patrols, snow removal, and food truck events at the converted park. Police did not take a central role in CE-CPTED activity in Carriage Town.

Level of resident control. Carriage Town neighborhood residents had low levels of control over CE-CPTED activities. Residents did not assume leadership roles in planning or implementing major $\mathrm{CE}$ CPTED revitalization activities. Rather, the UACC leadership initiated activities and invited residents to participate. The UACC leaders had not yet obtained sufficient funding or staffing for resident engagement at this stage of the coalition's development. Residents were also reticent to engage in CE-CPTED because they perceived that the UACC leaders were insufficiently responsive to resident concerns that the historic district boundary be preserved (Carmody, 2015).

\section{Stevenson Neighborhood}

The Stevenson neighborhood is a 0.21 square mile area (ESRI, 2019) that is home to Flint's largest public 
elementary school, the historic Atwood football stadium, and a number of small businesses, including a liquor store and auto repair shop. Housing in this neighborhood consisted of primarily single unit, detached homes interspersed with larger apartment complexes (U.S. Census Bureau, 2015a, 2015b). The neighborhood was characterized by the lowest population density and the highest poverty and vacancies of the three study neighborhoods following job and population loss and numerous demolitions of single-family homes (U.S. Census Bureau, 2015a, 2015b). While the Stevenson neighborhood experienced more poverty and vacancy than Carriage Town, it had more long-term residents who moved into the neighborhood prior to 2000. The UACC needs assessment identified this neighborhood as a hot spot for drug activity and violent crime (Berge \& Reischl, 2015). When CE-CPTED activity was initiated, the neighborhood had no existing neighborhood association (Berge \& Reischl, 2015).

CE-CPTED activities. CE-CPTED activities in the Stevenson neighborhood began in the second year of UACC coalition activity. At this stage, the UACC leadership had obtained federal funding for a project manager, a needs assessment, and more resident-engaged implementation strategies. During the UACC needs assessment, Stevenson residents provided insight into patterns of crime in their neighborhood and helped plan relevant CE-CPTED strategies. The UACC leadership provided resources to deploy these strategies, which included organizing local police patrols and supplying matching funds for an AmeriCorps team to assist with implementation. The AmeriCorps group led residents in beautification activities, such as cleanups, board-ups of vacant property, and clearing overgrowth to improve sightlines. Property remediation activities were a prominent focus of CE-CPTED implementation in this neighborhood due to the numerous vacant lots and vacant buildings in disrepair. AmeriCorps volunteers also conducted door-to-door outreach to distribute safety information and engaged residents in forming a neighborhood block club. Police took a more central role in CE-CPTED activity in Stevenson by helping to address criminal activity, close drug houses, and supervise cleanups and community events to enable residents to safely participate.

Level of resident control. Stevenson residents exerted moderate levels of control over CE-CPTED, as most activities were initiated by the UACC leadership but planned and implemented through a resident-engaged process. Resident control in Stevenson was established through resident involvement in the UACC needs assessment process, including interpretation of crime data and planning of relevant CE-CPTED strategies. Resident control was also established through UACC-supported efforts to form a neighborhood block club. The block club elected a neighborhood resident to serve as their president and engaged residents in planning and implementing CECPTED activities and events including a neighborhood block party. Moderate resident control in Stevenson was also facilitated by a grant that funded resident engagement in CE-CPTED planning and the hiring of a project manager focused on resident engagement.

\section{Mott Park Neighborhood}

The Mott Park neighborhood is a 0.44 square mile (ESRI, 2019) neighborhood located near the Kettering University campus. The neighborhood is home to a city park that includes a playground, tennis courts, picnic grounds, dry hockey rink, and amphitheater. Over $70 \%$ of housing units were single-family, detached homes (U.S. Census Bureau, 2015a, 2015b), and most were constructed in the 1940s by a subsidiary of the General Motors Corporation. This neighborhood had greater residential stability, lower vacancies, and more long-term residents than the Carriage Town and Stevenson neighborhoods. Yet, residential stability in this neighborhood was in decline with the neighborhood transitioning from primarily owner-occupied homes to more equal percentages of renter and owner-occupied homes (U.S. Census Bureau, 2015a, 2015b). The UACC identified this neighborhood as a hot spot for violent and property crime (Berge \& Reischl, 2015). The neighborhood had an active neighborhood association that organized a neighborhood watch program and cleanups prior to the start of CE-CPTED activity. These activities, however, were not sustained because residents grew frustrated with a lack of support from local organizations (Wyatt, 2017). The UACC's initiation of CE-CPTED strategies helped to engage supportive local organizations and re-energize these activities.

CE-CPTED activities. As implementation activities expanded across the Stevenson neighborhood in the coalition's third year, residents in Mott Park began to initiate independent CE-CPTED projects. At this stage in the coalition's development, UACC leadership, including Kettering University, was sufficiently well organized to support these resident-initiated strategies with technical assistance and supplies (e.g., boards, tools). Activities in this neighborhood included beautification and structural improvements to the neighborhood's central park, mowing of vacant lots, and formation of a neighborhood-led security patrol team. Neighborhood residents also formed a "blight squad" that adopted and remediated vacant properties by regularly mowing abandoned lots, boarding broken windows, and installing security lighting. The UACC-supported AmeriCorps team also assisted with door-to-door outreach and helped to organize 
neighborhood bike patrols and events. Police were not prominently involved in CE-CPTED implementation in Mott Park, as supplementary directed police patrols were planned but did not occur until after the conclusion of this study due to contractual delays.

Level of resident control. Resident control of CECPTED in Mott Park was high as residents initiated, planned, and led the implementation of CE-CPTED activities including the security patrol team and the blight squad's property remediation activities. Residents participated in the UACC needs assessment process to interpret crime data and determine the appropriate strategies to respond. Residents organized a blight squad to initiate CE-CPTED implementation, prior to the arrival of formal implementation support from the coalition. The group was self-organized, prioritized improvements, and coordinated the implementation of CE-CPTED. These efforts were supported and facilitated by UACC partners, including Kettering University and the AmeriCorps team, who provided CE-CPTED technical assistance and support. High resident control in Mott Park was facilitated by the hiring of the UACC project manager who focused on resident engagement and identified and coordinated needed support for resident-initiated CE-CPTED activities.

\section{Interview Sampling}

We conducted 19 interviews with 18 resident stakeholders and organizational partners from the University Avenue Corridor Coalition (UACC). We purposely sampled individuals who were involved in organizing or implementing CE-CPTED strategies. Our final sample included nine men and nine women, including 11 community residents who lived in the study neighborhoods and seven organizational partners who worked in the study neighborhoods but did not reside there. All of the residents interviewed were members of the UACC, and their level of involvement in community activities was representative of a typical coalition member. Organizational partners interviewed included members of law enforcement, a coalition project manager, leadership staff at UACC partner organizations, and members of a service corps involved in implementing CE-CPTED. We interviewed seven individuals in Mott Park, five individuals in Stevenson, and six in the Carriage Town neighborhood. One organizational partner was interviewed twice, about two different study neighborhoods. To recruit our sample, we asked the UACC project manager to identify an organizational partner or resident who held a leadership role in implementing CE-CPTED in each study neighborhood. After interviewing the neighborhood leads, we asked each one to identify additional participants involved in CE-CPTED implementation. Leads were asked to contact potential respondents to ask if they would be willing to be interviewed about their CPTED work. All participants invited by leads accepted these invitations. We asked each subsequent participant to identify additional prospective participants until we had recruited a gender-balanced sample of at least five respondents from each study neighborhood.

\section{Interview Procedure}

Interviews were conducted by a research associate for the evaluation study. The research associate provided an overview of the study to participants, and verbal consent was obtained prior to the start of each interview. The interviewer used a semi-structured interview protocol designed to assess community perceptions of CE-CPTED implementation and its effects on neighborhood conditions. Participants were asked to describe their neighborhood before CE-CPTED implementation began and their perceptions of how CE-CPTED interventions affected their neighborhood. Interviews were conducted in the fall of 2016 and lasted between 45 minutes and 1 hour. All interviews were audiotaped and transcribed verbatim. Procedures for the study were approved by the University of Michigan Institutional Review Board.

\section{Coding and Analysis}

To explore an association between CE-CPTED implementation, resident control, and busy streets outcomes, we adopted a systematic, directed content analysis approach described by Hsieh and Shannon (2005). Drawing on constructs from busy streets theory and prior research on CPTED, we developed a set of a priori codes for busy streets outcomes (Potter \& Levine-Donnerstein, 1999). To assess observable activity of busy streets, we coded for street activity including the presence of visible pro-social interaction (e.g., walking, cycling, recreation, resident conversations) and diminished use of streets for anti-social activity (e.g., drug use, crime). To assess social features of busy streets, we coded for sense of community, social cohesion, collective efficacy, social control, social capital, and behavioral action. Table 2 defines the codes we used in the analysis.

These codes represent the key exemplifying observable activity and social features described in busy streets theory (see Aiyer et al., 2015). The use of a priori codes derived from theory was intended to support an initial test of the propositions of BST that community-engaged physical change can catalyze features of busy streets. Langdridge (2007) suggests that applying a priori codes from theory and prior research can offer similar rigor and support generation of similar findings as more inductive methods. Our description below of the context for each of the three neighborhoods studied used three sources of 
information: (a) what the researchers know about the communities from working in them; (b) information from our local partners regarding the neighborhoods; and (c) summarized information from the respondent interviews that described their neighborhoods. We did not develop a priori codes for these data.

Coding was completed using the Dedoose qualitative analysis software (Dedoose, 2018). The research associate initially coded a subset of three interviews by chunking the interview transcripts into segments and applying a priori codes for observable activity and social features of busy streets (i.e., street activity, social capital, social cohesion). Two graduate student coders with no other role in the evaluation were trained by reviewing the codebook, meeting with the research associate to check for comprehension, and independently coding all segments from the three example transcripts. The study team met to discuss discrepancies in coding between the research associate and coders in training for all segments from the three example transcripts, to evaluate disagreements, and to come to consensus to enhance consistency by our coding team. Once coding agreement was established, the two trained coders independently coded the remaining interviews by applying a priori codes for observable activity and social features of busy streets. The two coders met again to discuss diversions in coding decisions and to evaluate disagreements. In instances where divergence in coding decisions persisted, the research associate and

Table 2 Physical and social features codes based on busy streets theory

\begin{tabular}{|c|c|c|}
\hline Code & Feature type & Description \\
\hline Street activity & $\begin{array}{l}\text { Observable } \\
\text { activity }\end{array}$ & $\begin{array}{l}\text { Use of streets for pro-social activity } \\
\text { (e.g., walking, biking, conversation); } \\
\text { diminished use of streets for } \\
\text { anti-social activity (e.g., criminal } \\
\text { activity, substance use, and loitering) }\end{array}$ \\
\hline $\begin{array}{l}\text { Sense of } \\
\text { community }\end{array}$ & Social & $\begin{array}{l}\text { Resident' perceptions about their } \\
\text { neighborhood, including sense of } \\
\text { belonging, pride, and morale }\end{array}$ \\
\hline $\begin{array}{l}\text { Social } \\
\text { cohesion }\end{array}$ & Social & $\begin{array}{l}\text { Connectedness among residents and } \\
\text { their willingness to help each other }\end{array}$ \\
\hline $\begin{array}{c}\text { Collective } \\
\text { efficacy }\end{array}$ & Social & $\begin{array}{l}\text { Residents' sense of belief that they } \\
\text { can take action to create safer and } \\
\text { more connected neighborhoods }\end{array}$ \\
\hline $\begin{array}{l}\text { Social } \\
\text { control }\end{array}$ & Social & $\begin{array}{l}\text { Resident efforts to communicate } \\
\text { standards of behavior that resist } \\
\text { illicit activity and other nefarious } \\
\text { behaviors }\end{array}$ \\
\hline $\begin{array}{l}\text { Social } \\
\text { capital }\end{array}$ & Social & $\begin{array}{l}\text { Supportive linkages between } \\
\text { neighborhood residents and more } \\
\text { resourced organizations and } \\
\text { institutions that provide resources } \\
\text { for community improvement }\end{array}$ \\
\hline $\begin{array}{l}\text { Behavioral } \\
\text { action }\end{array}$ & Social & $\begin{array}{l}\text { Individual or collective action to } \\
\text { improve neighborhood physical or } \\
\text { social conditions }\end{array}$ \\
\hline
\end{tabular}

coders met to come to consensus about the final codes that best fit the data segments in question. A segment was not assigned a code unless all three coders agreed that the construct was present in the text and no one coder held sway over the others in decision making. As a final check, the principal investigator checked the face validity of all codes for the constructs they were intended to represent.

The research associate grouped coded segments by neighborhood and by busy streets constructs to identify recurring themes across participants' responses. The coding team met a final time to confirm the assignment of coded segments to themes. Typically themes were not presented for discussion unless at least $40 \%$ of respondents endorsed the theme. Yet, salience was also considered a critical factor, such that divergent opinions that helped to illustrate the full spectrum of reactions to CE-CPTED were also presented for discussion.

\section{Results}

The most constructs consistent with BST were reported in the Mott Park neighborhood (7), followed by the Stevenson neighborhood (5) and Carriage Town (4). The percent of respondents who endorsed each theme is presented by study neighborhood in Fig. 2, with darker shades indicating higher percentages.

Street activity, sense of community, and collective efficacy were endorsed as themes associated with CE-CPTED implementation in all three study neighborhoods. Social capital and behavioral action were concentrated in the Stevenson and Mott Park neighborhoods, which had moderate to high resident control of CE-CPTED, while the theme of social cohesion was only reported in the Mott Park neighborhood. The detailed results by study neighborhood follow.

\section{Neighborhood Results}

Our neighborhood results are organized into three parts: respondents' descriptions of the study neighborhoods, and respondents' reported effects of CE-CPTED on observable activity and social features of busy streets. Quotations reported by residents are indicated with an $R$, and quotations reported by organizational partners are indicated with an $O P$.

\section{Carriage Town Neighborhood}

\section{Neighborhood Description}

Respondents reported pride about living in a historic district that was the birthplace of the auto industry and the site of GM's first factory. Residents and organizational 


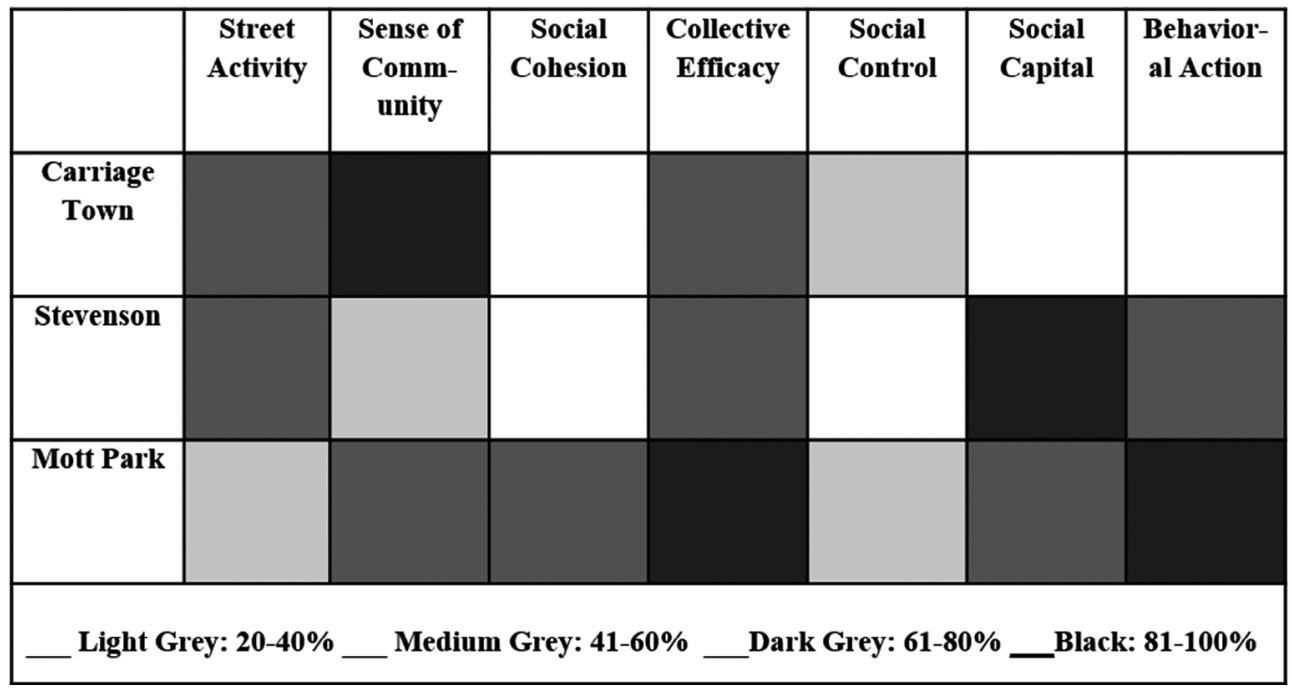

Fig. 2 Percent of respondents endorsing theme by neighborhood

partners were divided, however, about the best direction for revitalizing and transforming the neighborhood. The decision to revise the historic district boundary to facilitate demolition of deteriorating vacant structures created conflict and tension. Some respondents viewed the boundary revision as a critical step to remove abandoned structures that attracted crime and prepare the area for economic development. One resident believed, however, that demolition of historic structures (without concurrent attempts to refurbish existing buildings or encourage population infill) led to a loss of neighborhood identity and a diminished sense of community. Some residents were frustrated about UACC-led revitalization that failed to solicit community input about redeveloping the area. They complained about a lack of transparency in revitalization efforts and described a disconnect in which everyone has their own agenda, but communication between residents and the UACC is stymied.

\section{Observable Activity}

Residents and organizational partners in Carriage Town associated an improvement in street activity, including a reduction in loitering and trespassing, with the implementation of CE-CPTED strategies that included refurbishing 10 abandoned drug houses in strategic locations, installing parks, and closing a liquor store:

...that [CE-CPTED strategies] created even more neighborhood activity and it encouraged people coming out more. From those spots, from those crack houses, there wasn't really any neighborhood activity it was just the loitering. But then [after CE-CPTED strategies were implemented] there were more people living there, more homeowners, more renters, now the loiterers are not there anymore. I would definitely say that an increase in positive street activity has happened.

It just changed, there weren't people hanging around outside the party store. I had another neighbor in the area who said that they had actually planted huge sections of blueberry bushes with all the thorns because there were so many people cutting through their property all the time to go to the party [liquor] store from the neighborhood nearby. They said, "wow when you closed that, I wouldn't have needed all those blueberry bushes" because that traffic just stopped.

One resident was concerned, however, that organization-led CPTED projects that did not take resident desires into account in the design process were associated with diminished use of public spaces:

Well [community park] was put in a place where...there's no resident activity, there's no draw it's basically a flat surface why am I going to go to a flat surface? I have no problem with projects but it's how are these projects going to be utilized... There's no playground so you're not going have kids going there. There's a couple of park benches but I mean if I'm going to sit outside I'm probably going to sit outside next to [local business].

\section{Social Features}

Residents in Carriage Town reported that physical CPTED changes to eliminate the blighted, vacant lot and liquor 
store, and install a pristine park increased their sense of community.

I think this pride of it, keeping it clean, it overflows to everyone...Well, it certainly encouraged us to be happy there.

Both residents and organizational partners reported that CE-CPTED focused on beautification and physical improvements enhanced their perceptions that good things were possible. This sense of hopefulness and energy encouraged neighbors to remain invested in their community (sense of community) and enhanced their collective efficacy:

...it's not just about crime prevention, it's also about creating a sense of brightness and hope because you are clean and constantly getting better.

It gives that appearance of something happening, something good coming. . the perception that maybe encouraged people to be part of the community...helped our state of community, saying "you know, I can handle this."

Yet, some residents felt that CPTED strategies that were supported by the UACC leadership, such as the decision to revise the historic district boundary and subsequent demolition activities, had an adverse effect on neighborhood identity and sense of community:

When they lifted the historic designation over on our side, that's when they really started demo-ing these buildings, and so now you have a lot of empty spaces and just a few random houses sticking up...There's no houses there, there's no people, so I'm like I'm not going to go down there because I don't know what's going to be down there... There's no trees, there's no vegetation, it's just green space, it just kind of leaves you with this empty feeling inside....you don't feel like you're a part of a neighborhood.

Carriage Town organizational partners and residents also reported that they used CE-CPTED to communicate standards for property maintenance. They noted that CECPTED strategies, including property beautification and surveillance, exerted social control that conveyed expectations for maintenance, removed excuses for poor property upkeep, and encouraged neighbors to keep up with the new standard:
We paint constantly just to make stuff look fresh. The message is that there are people that live here, there are people that care, and that those people that are engaged in entropy will not win in the fight against life.

By the removal of the liquor store, it was like night and day because these individuals had to move elsewhere, but it also allowed a very few in this community to see what was going on...it just goes to show who owns what properties around here and if you're not willing to invest in those properties then you are part of the problem yourself...there's constant surveillance, and that gives you a sense of purpose also.

\section{Stevenson Neighborhood}

\section{Neighborhood Description}

Residents and organizational partners described Stevenson residents as reclusive, keeping to themselves, and rarely participating in outside activities. Respondents attributed this reclusive behavior to negative activity surrounding a liquor store, drug houses in their neighborhood, and fears of retribution for reporting crimes or interacting with police. Respondents noted that residents were distrustful of police due to historically slow response times and inconsistent presence in the neighborhood. They described residents in this community as interested in improving their community but lacking a critical mass to create change due to low residential population, few economic resources, and a lack of a formal organizing body, such as a block group or neighborhood association.

\section{Observable Activity}

Organizational partners reported a reduction in negative street activity including substance use and an increase in positive activity, including more children and families feeling comfortable and safe walking on the streets or using their front yards:

There's definitely more street activity. People walking...we didn't have that before. You know... what you saw before was a lot of open alcohol, people with beer cans in paper bags, and cars slowing, stopping, talking to people...indicative of an open-air drug market.

With gun violence in the area, there was just a fear of even being out in the community, of being outside the home...So this guy has a wife and a newborn baby and now all of a sudden he is out in front of his home, 
barbecuing and spending time with his family, whereas before he wouldn't have done that. I see it happening more and more.

Some organizational partners associated an increase in positive street activity, including walking, with the multiple CE-CPTED projects occurring in the neighborhood including directed police patrols and bike patrols that increased organized surveillance:

I see a lot of Stevenson residents walking around and it seems like they are not afraid to walk outside. Yeah, there is a lot more street activity since we've been doing bike patrols, river patrol watches.

\section{Social Features}

Stevenson organizational partners noted that CE-CPTED efforts to close drug houses increased morale and positive sense of community:

So I think in that particular pocket [where drug houses were shut down] there has been a huge positive transition in attitude or perception of their community.

Community-organizing support from the AmeriCorps group and local police on CE-CPTED projects helped residents in this low-density area recognize that they were not alone (social capital) and encouraged them to feel that they could improve their neighborhoods and play a role in neighborhood problem solving (collective efficacy, behavioral action):

People just really needed to see that, hey, somebody does care about this other than just us. We are not in this alone and as long as we are not in this alone, we will take ownership and responsibility in this and we will do it.

We (AmeriCorps members) were offering support to help establish the block club in the area... she (local resident) jumped right on it. She didn't want to sit still, be idle, and just complain. She wanted to actually get her hands dirty and you know, actually be a part of the change.

After the AmeriCorps group and local police began to organize and support CE-CPTED efforts in the neighborhood, Stevenson residents who were reclusive and withdrawn began voicing their concerns and participating in neighborhood improvement efforts (collective efficacy, behavioral action):

I think residential engagement has changed a lot. They are very opinionated now. When I first joined [AmeriCorps] I noticed that some residents were like what's the point. It's not gonna change the problems I see day to day... After they saw what we [AmeriCorps] can do they were like okay "I can voice my opinions."

Residents very early on were very hesitant to speak out, and as things have started to systematically become better in that area they are coming out, they are having more of a voice they are electing a president next week at their block club.

Stevenson residents and organization partners reported that CE-CPTED activity, particularly physical improvement and property maintenance, inspired nearby residents to engage in neighborhood improvement projects (behavioral action). Many neighbors independently offered their help to support or expand cleanup activity:

We are doing the cleanups then we see somebody else come out and go get their garden tools and they start working on their yard...it's silent but you see it. And then the next time more people come out to help us do it. . .it spreads.

And so from those three series of [property] cleanups we had residents come out and clean not only their properties but also came out and cleaned additional properties that were not even on our list to clean...

I've noticed that residents are like "oh let me be a part of that." We actually had a resident come out with a chainsaw and help us cut down trees. We didn't give him any notification or tell him what we were doing or anything, he just came on to the site and got to work.

(OP)

\section{Mott Park Neighborhood}

\section{Neighborhood Description}

Respondents described Mott Park as a neighborhood in transition. The neighborhood had experienced an increase in renter-occupied homes and deteriorating properties as aging residents passed away and homes remained vacant in a poor economic climate. Some residents were disillusioned with police for slow responses and an inconsistent 
presence in the neighborhood. Organizational partners and residents reported tensions over who should be responsible for neighborhood improvement efforts, with many residents feeling that local institutions should take a greater role in supporting and facilitating revitalization activity.

\section{Observable Activity}

In the Mott Park neighborhood, residents reported an increase in street activity, specifically recreational use of streets and bike pathways and families using public spaces and trails:

There are cues. And the walking path, the bicycle path, the one that is on Chevrolet, and the new park gets used a lot in summer.

And so they will cross through the bicycle path and it will be some families with bicycles and little kids. That would have never happened two years ago.

\section{Social Features}

Mott Park residents reported that the physical upgrades achieved through CE-CPTED activities had an immediate positive effect on residents' morale and sense of community:

That right there [physical upgrades to local corner store] in itself has lifted so many people just because it doesn't look like it's run down anymore.

Walking by and seeing the changes is very satisfying and does something good for the soul I guess.

It's cleaner, it's brighter, feels better, feels more like a neighborhood people love and care about. I think that is helpful.

Residents reported that engaging in CE-CPTED activities together enhanced their bonds and attachment to their neighbors (social cohesion):

I think that for all of us it has improved our perception of the neighborhood by doing this together and making more friends, seeing that there's more people who love this neighborhood...

Seeing that neighbors cared about their environment enhanced their bonds with neighbors, which promoted more hopeful attitudes about their neighborhood environment (social cohesion and sense of community):

...everybody feels like we are growing closer as a community at least knowing that hey there's good people out here and a lot of people willing to help. Before it was kind of doom and gloom, like "oh man crime is rising, the neighborhood is horrible" ... It's giving a little bit of a different perspective now...

Engaging in CE-CPTED activities helped Mott Park residents build connections based on mutual trust and support (social capital). Residents showed a greater willingness to help each other and reach shared neighborhood objectives. We observed this theme through the efforts of the Mott Park Blight Squad, a neighborhood group that organized a Facebook page where neighbors could ask for help and share resources to clean up their neighborhood:

They know we are working in an area "oh you guys are working on this house, I'm dropping off some lawn bags. I can't physically help you, but I'm going to help you by donating or if you need a rake I'm going to bring you a rake."

It's like you have an abandoned house, and you don't have the tools, but right now you have these 4 or 5 guys that are coming together and people donate things, and people help them, so there is this spreading effect of pride.

Residents reported that resident-led CE-CPTED efforts in Mott Park helped to establish patterns of help-seeking and mutual support (social capital) that were not previously observed in the neighborhood:

Especially with the Mott Park Squad...people are more involved and they are doing things that alone they would have never done.

...we [Blight Squad member] talk to all kinds of people now, we have had neighbors come and talk to us. We have had people in the community reaching out for help that maybe wouldn't have before.

Mott Park residents reported that witnessing people from their community engaged in implementing $\mathrm{CE}$ CPTED inspired their investment in their community and fueled their sense of hopefulness about its future (collective efficacy): 
I think it has inspired them and it's also given them hope and energized that a bit more because they see people caring about what's going on and it's not strangers. It's people who live in the neighborhood taking their time... that makes a difference." It makes me feel better to be where I'm at.

There's a team of 10 men who have scraped, painted, pulled out wild brush, put in lighting, boarded up squatter homes...they call themselves the blight squad and it's been a fantastic boon to our neighborhood because now we feel like we've got this band of rogue heroes who are trying to do this...I think it gives us hope, and it makes us feel like someone cares. ...now people are feeling energized and have a glimmer of hope that things are changing and are starting to head in a positive direction, cause they can actually see it, and not only can they see it, now a lot of people in the community are actually a part of it, so that helps.

Mott Park residents reported that they used CE-CPTED activities like beautification to communicate ownership and stewardship of an area and to encourage residents to keep up with maintenance standards (social control):

I think when you start to clean, you start to tell people that you care...there's somebody looking or somebody seeing. The other thing is when I clean my street I do more than clean my street, I'm sending the message that we care or that there are behaviors that we are trying to get people to emulate.

Establishing linkages to community organizations such as Kettering University that provided supplies and other instrumental support for resident-led efforts increased a sense of solidarity and balanced ownership for problem solving (social capital and collective efficacy):

Before, the social environment would be trying to figure out how Kettering University had a role, and now it's "we're in it together," so there a lot of momentum.

(OP)

I feel like [support from Kettering] it's kind of been a shot in the arm, like an antibiotic or a steroid. Not just knowing you have an ally in some ways, but really knowing that you do have an ally that has the same interest as you.

Residents reported that this sense of shared ownership between neighborhood residents and UACC partner organizations inspired greater resident involvement in neighborhood improvement activities (social capital and behavioral action):

...ok, there are all these great movements going on, why are we just sitting here and waiting?" Let's get out there and help it along.

... the Blight Squad kicks in and the grass getting mowed... and then the [AmeriCorps group] coming in on board...now that's really been helping or encouraging, inspiring people to get back involved. We're starting to see more people say, "Hey I want to be involved" or "what do I need to do?"

Residents often described the implementation of CECPTED, particularly maintenance of properties, as a positive contagion that motivated further action (behavioral action):

People kind of catch it and get excited about it.

It's grown slowly but what I would like to see is what is happening now, where you don't necessarily have to belong to it. You could have a splinter group and do your own thing... I was calling it the fever of blight...the blight elimination fever and that's what I hope. I hope everybody catches it.

The positive, contagious effect of physical CPTED was not confined to individual neighborhoods. Residents reported that property maintenance and cleanups radiated to other communities and occasionally inspired external groups to enter communities and support change efforts, or expand efforts to their own communities (behavioral action):

We've seen other people come into the neighborhood and do cleanups that don't even live there anymore, maybe they have roots there. We saw another neighborhood association, they saw what we were doing and started doing cleanups in their neighborhood.

\section{Discussion}

Our results support busy streets theory (BST) because they repeatedly indicated that community-engaged neighborhood improvement can be infectious. Consistent with BST, our results suggest that community-engaged crime 
prevention through environmental design (CE-CPTED) may be a particularly potent process for fostering social features that comprise an empowered community. This was evidenced by our finding that CE-CPTED helped to increase residents' sense of community, collective efficacy, social cohesion, social control, social capital, and behavioral action (Aiyer et al., 2015). Respondents across neighborhoods defined by different levels of resident control in CE-CPTED planning and implementation noted that their collective work was helpful to create observable activity indicative of a busy street. They also noted that the CE-CPTED process helped communicate that people cared about their neighborhood and were watching out for each other. Thus, the results support the idea that community and organizational collaboration in creating safe and thriving neighborhoods where residents feel connected to each other, interact in positive ways, and work together can help create conditions for busy streets and community empowerment (Aiyer et al., 2015).

Our results also suggest that neighborhood transformation is unlikely to occur spontaneously in low-resource contexts where disorder and fear are high, and neighborhood trust and cohesion are low. This is also consistent with BST, which asserts that neighborhoods experiencing structural disadvantage may require an intentional effort, supportive structures, and alignment of organizational support to facilitate the development of busy streets (Aiyer et al., 2015). We found that coalition-supported CECPTED encouraged residents in Stevenson and Mott Park to engage in a structured process of neighborhood change to improve and secure their physical environment while collaborating with neighbors to design and implement these physical changes. This engagement, in turn, helped to foster indicators of the foundational features of busy streets (e.g., social cohesion, collective efficacy, social control).

Respondents in all three neighborhoods reported that CE-CPTED was associated with a reduction in negative street activity, including loitering and substance use, and an increase in positive observable street activities such as walking, biking, and informal social interactions. In order to create a busy street, it may be vital to reduce anti-social behavior before more positive observable behavior can take root. Reduced negative activity and increased positive street activity are important signposts of busy streets because they suggest a safe context where informal social interaction and positive neighborly interactions can flourish. Increased opportunities for positive interactions reinforce social capital, collective efficacy, and social control (Aiyer et al., 2015).

Our results suggest that CE-CPTED facilitated an enhanced sense of community and morale in all three neighborhoods. Property maintenance activities were also frequently described across neighborhoods as a behavioral catalyst that inspired neighborhood beautification beyond originally planned activities. Yet, not all changes were well received. When residents perceived that CE-CPTED interventions were organization-led and did not incorporate sufficient resident input, they were more likely to report less use of physical spaces and less development of a sense of community and cohesion than respondents in neighborhoods with more resident input and control. These results suggest that CE-CPTED efforts that are organization-driven, expeditious, and insufficiently inclusive may actually undermine the empowered outcomes of busy streets. CE-CPTED strategies may facilitate empowered outcomes for participants involved, but they may also reveal community conflicts and divisions about desired directions for community revitalization. The origins and potential resolutions of these conflicts may be viewed through the lens of community development.

Bhattacharyya (1995) suggests that the central goal of community development is to create agency and solidarity that supports people to order their world. To achieve this central goal of community development, Hustedde and Ganowicz (2002) argue that neighborhood initiatives must establish shared meanings and redress power imbalances and unequal control over decision making. Our results also support this idea as we found that respondents who were less involved in the defining, planning, and implementing CE-CPTED activities reported less collective efficacy and ownership of the changes made than respondents in the neighborhoods where a more shared process for revitalization took place. Thus, resident control over CE-CPTED is a vital ingredient to ensure local relevance and acceptability. Resident control differentiates CE-CPTED from more traditional forms of physical CPTED and gentrification, which may push out long-time residents, disrupt social ties, and lead to the loss vibrant community spaces (Cozens \& Love, 2017; Hollander \& Whitfield, 2005; Versey, 2018). We found that the more influence and control respondents had on the CE-CPTED activities, the more likely they felt that they were improving the neighborhood and increasing social connections. These findings suggest that higher levels of resident control in CE-CPTED process can be a catalyst for community empowerment.

Aiyer et al. (2015) identify three components of community empowerment that promote busy streets. The intracommunity component of community empowerment includes neighborhood perceptions including respondents' sense of community, social cohesion, and collective efficacy. Residents and organizational partners in all three neighborhoods frequently mentioned these features when they spoke about how CE-CPTED activities enhanced their investment and belonging to their neighborhood and 
improved social relationships. The interactional component of community empowerment includes building social capital for revitalization and collaboration with community institutions. This component was evident in Stevenson and Mott Park, where residents and partner staff collaborated with UACC partners, including AmeriCorps and local police on CE-CPTED initiatives. The behavioral component of community empowerment includes strengthening actions residents take to improve neighborhood conditions. The behavioral component was especially evident in the Stevenson and Mott Park neighborhoods where both residents and organizational partners reported that witnessing CE-CPTED activities motivated others to take similar action. CE-CPTED may, therefore, be considered an empowering process because it helps participants develop skills and decision-making power, connects them with the organizational resources, and provides them with opportunities to take collective action to make the neighborhood change they want to see (Zimmerman, 1995).

Features of busy streets, however, may also emerge due to structural characteristics of neighborhoods such as residential stability and socioeconomic resources that predispose neighborhoods to have social capital, social control, and collective efficacy (Elliott et al., 1996; Sampson, Morenoff, \& Earls, 1999; Sampson et al., 1997). Thus, one alternative explanation for our findings is that features of busy streets were already more concentrated in the Stevenson and Mott Park neighborhoods due to existing structural characteristics.

Yet, we believe our results are not explained away by structural differences alone for several reasons. First, despite variation in some structural features, all three neighborhoods were highly disadvantaged contexts with poverty and vacancy far surpassing state and national averages (U.S. Census Bureau, 2015a, 2015b) and represented crime hot spots in Flint (Berge \& Reischl, 2015). Thus, while the study neighborhoods differed somewhat within similar types of neighborhoods, relative to other more advantaged neighborhoods, their differences paled in comparison. Second, residents and organizational partners reported features of busy streets in all three neighborhoods in direct reaction to CE-CPTED implementation. Although we found some differences across neighborhoods, in ways consistent with structural features, the differences that respondents reported were more about the level of resident control over CE-CPTED than structural characteristics of the neighborhood. Finally, respondents in the Stevenson neighborhood, which was the least populous and most economically disadvantaged neighborhood in our analysis, reported more social features of busy streets than respondents in Carriage Town. Stevenson residents had a moderate level of resident control over CE-CPTED activities and reported constructs of busy streets at levels similar to
Mott Park neighborhood respondents, which had greater residential stability and economic resources. This suggests that a structural explanation alone does not account for our findings because Stevenson residents should have reported the least amount of social cohesion, collective efficacy, and behavioral action among the neighborhoods we studied.

\section{Limitations}

Our study has several limitations that require attention. One limitation is our relatively small sample size that primarily included respondents involved in organizing and implementing CE-CPTED work. This may limit the generalizability of our findings and may have predisposed the results to favor a positive outlook on CE-CPTED and busy streets outcomes. Our interview protocol, however, was openended and did not prompt for specific BST constructs. The responses generated were genuine feelings and perceptions from the CE-CPTED work in which respondents were engaged. Nonetheless, our study suggests that future research that includes a larger and a more random sample of residents, especially those with more marginal roles in the CE-CPTED activities, would be informative to assess just how infectious CE-CPTED is for generating busy streets.

Second, we drew our data from only three neighborhoods located in one economically challenged city. This further limits the generalizability of our findings, but these Flint neighborhoods are not that dissimilar from neighborhoods in other northern U.S. rust belt cities that have experienced economic declines (Feyrer et al., 2007; Schilling \& Logan, 2008).

Third, our a priori coding scheme may have biased responses toward a more positive than critical analysis of busy streets theory constructs and neighborhood change. Although applying a priori codes driven by theoretical constructs is an acceptable approach (Langdridge, 2007), the fact that BST stresses positive social interaction may have influenced our analysis to find more positive experiences and may not have drawn out more critical perspectives. Yet, we did find some discordant results and they were in the neighborhood where we would expect the most critical analysis because residents had the least amount of control in the CE-CPTED planning process. Nevertheless, future research that includes explicit questions about the challenges associated with implementing CE-CPTED and its adverse effects would be useful.

Finally, this study did not directly examine how police involvement in CE-CPTED efforts affected community and police relationships. We suggest future studies that evaluate the types and intensity of police involvement in CE-CPTED that might promote positive community and police relationships as an important direction for future 
research. These limitations notwithstanding, our study represents one of the few empirical studies of a communityengaged approach to CPTED and provides initial evidence for busy streets theory.

\section{Conclusion}

The results of our study support the notion that community engagement and resident control in physical revitalization of neighborhoods may be a fruitful approach to rebuilding communities devastated by years of economic decline and political neglect. They also support the utility of busy streets theory (BST) to describe how CE-CPTED activities can promote community empowerment. Our findings suggest that that the process of physically revitalizing neighborhoods can help empower community residents and organizational stakeholders to mobilize resources to improve quality of life and promote safe neighborhoods especially in the context of structural disadvantage. While respondents reported features of busy streets in all three study neighborhoods in reaction to $\mathrm{CE}$ CPTED, the greatest number of busy streets outcomes was reported in the Mott Park neighborhood, which benefited from more long-term residents and the full development of CE-CPTED strategies and resources. CE-CPTED is a relatively low-cost, accessible, and participatory approach to neighborhood revitalization that can be widely replicable for neighborhood transformation. Yet, we also found that external organizational support that attends to the structural context of neighborhoods is necessary to help neighborhoods succeed in their efforts to make their streets safer and more cohesive. Our study suggests that CE-CPTED provides one small step in helping neighborhoods reemerge as vibrant busy streets.

\begin{abstract}
Acknowledgments We thank our community partners and the respondents in Flint for their time and willingness to share their perspectives. We also extend our thanks to research assistants, Mikala Cox, Sophie Steinbock, and Jacqueline Dighero for their contributions to this manuscript. This study was conducted as part of a federally funded evaluation of crime prevention through environmental design (CPTED) in Flint, Michigan (Grant numbers 1R01CE002552-01 from the Centers for Disease Control and Prevention; 2014-AJ-BX-011 from the Department of Justice). The authors of this study include individuals who have conducted research in Flint for 25 years and who have worked closely with the CPTED initiative that is the focus of this study. Coauthors include evaluators of the initiative since its inception and the project manager for the initiative under study. The results reported in this study do not necessarily represent the views of the CDC or DOJ.
\end{abstract}

\section{Conflict of Interest}

The authors declare that they have no conflict of interest.

\section{References}

Abdullah, A., Hedayati Marzbali, M., \& Maghsoodi Tilaki, M. J. (2013). Predicting the influence of CPTED on perceived neighbourhood cohesion: Considering differences across age. Journal of Environmental Psychology, 36, 54-64.

Aiyer, S. M., Zimmerman, M. A., Morrel-Samuels, S., \& Reischl, T. M. (2015). From broken windows to busy streets a community empowerment perspective. Health Education and Behavior, 42, 137-147.

Arnstein, S. (1969). A ladder of citizen participation. Journal of American Planning Association, 35, 216-224.

Berge, L., \& Reischl, T. M. (2015). Renew the avenue implementation plan: A crime prevention program of the university avenue corridor coalition (UACC). Flint, MI: Kettering University.

Bhattacharyya, J. (1995). Solidarity and agency: Rethinking community development. Human Organization, 54, 60-69.

Carmody, S. (2015, January 16). Flint's Carriage Town neighborhood weighs proposal to shrink its historic district. Available from: https://www.michiganradio.org/post/flints-carriage-townneighborhood-weighs-proposal-shrink-its-historic-district [last accessed March 22, 2019].

Coleman, J. S. (1988). Social capital in the creation of human capital. American Journal of Sociology, 94, S95-S120.

Cozens, P., \& Love, T. (2015). A review and current status of crime prevention through environmental design (CPTED). Journal of Planning Literature, 30, 393-412.

Cozens, P., \& Love, T. (2017). The dark side of crime prevention through environmental design (CPTED). Oxford Research Encyclopedia of Criminology and Criminal Justice. https://doi. org//10.1093/acrefore/9780190264079.013.2

Crowe, T. D. (2000). Crime prevention through environmental design: Applications of architectural design and space management concepts (2nd edn). Oxford, UK: Butterworth-Heinemann.

Dedoose (Version 8.0.35). (2018). Available from: www.dedoose.com

Durkheim, E. (1997). The division of labor in society. New York: Free Press.

Elliott, D. S., Wilson, W. J., Huizinga, D., Sampson, R. J., Elliott, A., \& Rankin, B. (1996). The effects of neighborhood disadvantage on adolescent development. Journal of Research in Crime and Delinquency, 33, 389-426.

ESRI (2019). ArcGIS Pro (Version 2.2). ESRI.

Feyrer, J., Sacerdote, B., Stern, A. D., Saiz, A., \& Strange, W. C. (2007). Did the Rust Belt Become Shiny? A Study of Cities and Counties That Lost Steel and Auto Jobs in the 1980s/Comments. Brookings-Wharton Papers on Urban Affairs; Washington, 41-102.

Fonger, R. (2014a, November 14). Shrink Flint's Historic Carriage Town? New report suggests removing 10 blocks. MLive. Available from: https://www.mlive.com/news/flint/2014/11/shrink_f lints_historic_carriag.html [last accessed March 22, 2019].

Fonger, R. (2014b, December 4). Preservation of Flint's historic Carriage Town under discussion as report suggests shrinking. MLive. Available from: https://www.mlive.com/news/flint/2014/ 12/groups_supporting_preserving_c.html [last accessed March 22, 2019].

Frohlich, T. C. (2016). America's Fastest Shrinking Cities. Available from: 247wallst.com website: http://247wallst.com/special-re port/2016/04/04/americas-fastest-shrinking-cities-3/ [last accessed February 20, 2017].

Garvin, E., Branas, C., Keddem, S., Sellman, J., \& Cannuscio, C. (2013). More than just an eyesore: Local insights and solutions on vacant land and urban health. Journal of Urban Health, 90, $412-426$.

Genesee County Health Department (2013). 2013 Survey General Information | Speak To Your Health! Community Survey Data 
[Survey]. Available from: http://speak.gchd.us/ [last accessed November 27 2017].

Hollander, J. B., \& Whitfield, C. (2005). The appearance of security zones in US cities after 9/11. Property Management, 23, 244256.

Hsieh, H.-F., \& Shannon, S. E. (2005). Three approaches to qualitative content analysis. Qualitative Health Research, 15, 12771288.

Hustedde, R. J., \& Ganowicz, J. (2002). The basics: What's essential about theory for community development practice? Journal of the Community Development Society, 33, 1-19.

Jacobs, J. (1961). The death and life of great American cities. New York: Vintage Books.

Kelling, G. L., \& Coles, C. M. (1997). Fixing broken windows: Restoring order and reducing crime in our communities. New York: Simon and Schuster.

Kildee, D., \& Hovey, A. (2019). Land Banking 101: What is a Land Bank. Available from: U.S Department of Housing and Urban Development Neighborhood Stabilization Program website: https://www.hudexchange.info/resources/documents/LandBank ingBasics.pdf [last accessed March 30, 2019].

Kubrin, C. E., \& Weitzer, R. (2003). New directions in social disorganization theory. Journal of Research in Crime and Delinquency, 40, 374-402.

Kuo, F. E., Sullivan, W. C., Coley, R. L., \& Brunson, L. (1998). Fertile ground for community: Inner-city neighborhood common spaces. American Journal of Community Psychology, 26, 823-851.

Langdridge, D. (2007). Phenomenological psychology: Theory, research, and method. Harlow, UK: Pearson Education.

McMillan, D. W., \& Chavis, D. M. (1986). Sense of community: A definition and theory. Journal of Community Psychology, 14, 6-23.

Newman, O. (1972). Defensible space; crime prevention through urban design. Available from: http://hdl.handle.net/2027/ [last accessed October 15, 2018].

Newman, O. (1973). Crime prevention through urban design defensible space. Oxford, UK: Macmillan.

Newman, O. (1996). Creating Defensible Space. Available from: http://www.defensiblespace.com/book.htm [last accessed October 15, 2018].

Perkins, D. D., \& Zimmerman, M. A. (1995). Empowerment theory, research, and application. American Journal of Community Psychology, 23, 569-579.

Peterson, N. A., \& Zimmerman, M. A. (2004). Beyond the individual: Toward a nomological network of organizational empowerment. American Journal of Community Psychology, 34, 129-145.

Potter, W. J., \& Levine-Donnerstein, D. (1999). Rethinking validity and reliability in content analysis. Journal of Applied Communication Research, 27, 258-284.
Reynald, D. M. (2011). Factors associated with the guardianship of places: Assessing the relative importance of the spatio-physical and sociodemographic contexts in generating opportunities for capable guardianship. Journal of Research in Crime and Delinquency, 48, 110-142.

Sampson, R. J., \& Laub, J. H. (1995). Crime in the making: Pathways and turning points through life. Cambridge, MA: Harvard University Press.

Sampson, Robert J., Morenoff, J. D., \& Earls, F. (1999). Beyond social capital: Spatial dynamics of collective efficacy for children. American Sociological Review, 64, 633-660.

Sampson, R. J., Raudenbush, S. W., \& Earls, F. (1997). Neighborhoods and violent crime: A multilevel study of collective efficacy. Science (New York, N.Y.), 277, 918-924.

Sarason, S. B. (1974). The psychological sense of community: Prospects for a community psychology. Cambridge, MA: Brookline Books.

Saville, G., \& Cleveland, G. (2013). Second-Generation CPTED. In 21st Century Security and CPTED (Vols. 1-0, pp. 91-106). Available from: https://doi.org/10.1201/b15046-8

Schilling, J., \& Logan, J. (2008). Greening the rust belt: A green infrastructure model for right sizing america's shrinking cities. Journal of the American Planning Association, 74, 451-466.

Skjaeveland, O., \& Garling, T. (1997). Effects of interactional space on neighbouring. Journal of Environmental Psychology, 17, 181-198.

U.S. Census Bureau (1960). U.S. Censuses of Population and Housing. Available from: U.S Census Bureau website: https:// www.census.gov/library/publications/1961/dec/population-andhousing-phc-1.html [last accessed March 20, 2019].

U.S. Census Bureau (2015a). American Community Survey 5-Year Estimates. Available from: https://www.census.gov/programssurveys/acs/ [last accessed February 27 2017].

U.S. Census Bureau ( 2015b). ACS 2015 (5-Year Estimates). Available from: https://www.socialexplorer.com/tables/ACS2015_5yr/ R12095295 [last accessed March 20, 2019].

U.S. Census Bureau (2016). ACS 2016 (1-Year Estimates). Available from: Social Explorer website: https://www.socialexplore r.com/tables/ACS2016/R12127354 [last accessed March 20, 2019].

Versey, H. S. (2018). A tale of two Harlems: Gentrification, social capital, and implications for aging in place. Social Science and Medicine, 214, 1-11.

Wilson, J. Q., \& Kelling, G. L. (1982). Broken windows. Atlantic Monthly, 249, 29-38.

Wyatt, T. (2017, January 30). Interview on Mott Park.

Zimmerman, M. A. (1995). Psychological empowerment: Issues and illustrations. American Journal of Community Psychology, 23, 581-599. 